\title{
Sociologia da sociologia da exclusão social
}

\author{
VaLÉRIA Márcia QueIROZ*
}

\begin{abstract}
R esumo: O presente trabalho proara disatir a exclusão social sob o prisma da Sociologia do Conhecimento. Nesse sentido, fundamentando-se em Merton, que defende que essa ciência interessa-se pelas relaçães entre o conhecimento e autros fatores existenciais da sociedade, o artigo apresenta um histórico do desenvolvimento do debate teórico acerca do tema, disartindo a questão da exclusão social tendo como referência dbis estudiosos brasileiros: Elimar Pinheiro do Nascimento e Pedro Demo. Correlaciona ainda a base existencial da produção desses teóricos com as suas respectivas producões intelectuais.

Palavras-chave: exclusão social; teoria sociológica; gldbalização.
\end{abstract}

\section{A presentação}

A Sociologia do Conhecimento, segundo M erton (1970), interessa-se primordialmente pelas relações entre o conhecimento e outros fatores existenciais da sociedade ou da cultura. Por considerar que a exclusão social (ES) está, hoje, disseminada internacionalmente, tanto em expressão como em debate, pretende-se neste trabalho fazer a sociologia da sociologia da exclusão social.

Para tanto será traçado, primeiramente, um histórico do tema, apresentando o desenvolvimento do debate teórico sobre essa questão. Em seguida, serão anal isadas as obras de dois estudiosos brasileiros, Elimar Pinheiro do Nascimento e Pedro Demo, pelo fato de esses pesquisadores analisarem 0 mesmo objeto social por ângulos diferenciados, propondo soluções também diferentes para o mesmo problema. $\mathrm{Na}$ análise de suas obras, serão apontados os fatores responsáveis por esse problema e as soluções propostas por cada um deles e, ainda, será correlacionada a base

\footnotetext{
* M estranda em Sociologia na UFG.
}

existencial dessa produção com as suas respectivas produções intelectuais.

\section{Histórico do conceito exclusão social}

0 termo exclusão social surge e torna-se corrente na $F$ rança durante os anos 80.0 termo "novos pobres", até então predominante, cede lugar à expressão "excluídos" após a obra Les exclus (1974), de L enoir, que define os excluídos como "resíduos que o desenvolvimento dos 'trinta anos gloriosos' parecia esquecer" (apud Nascimento, 1994, p. 289).

Durante o governo de François M iterrand, a ES tomou-se tema de exposições, cursos, seminários, livros, revistas e jornais. Contudo, a discussão do assunto está rel acionada apenas a duas esferas básicas: a do mundo do trabalho e a da sociabilidade.

Sendo assim, Touraine (1991) entende o fenômeno da exclusão social como fruto do aumento da desigual dade social, em uma sociedade que substituiu a verticalidade do conflito capital versus trabalho pela horizontalidade: conflito entre os que estão de dentro e os que 
estão fora do mercado. Para o diretor da É cole des Hautes Études en Sciences Sociales, a ES é o sinal de uma sociedade dilacerada e marcada por um radical processo de mutação social. Já Castel (apud N ascimento, 1994) entende a ES como uma trajetória de vida caracterizada por um processo de dessocialização e desfiliação política e define o excluído como:

o indivíduo sem trabalho e sem família ou outros laços primários. Obrigado a se deslocar em busca do trabalho, desintegra-se socialmente. Sem trabal ho perde o nome, a identidade, os vínculos comunitários e sociais. Torna-se 0 vagabundo moderno, o marginal, enfim, 0 excluído. (Idem, ibidem)

No conjunto, podemos afirmar que, para os teóricos franceses, a ES representa uma ruptura com as expectativas imperantes nos anos 60 quando prevalecia a idéia de uma dinâmica social que possibilitaria a integração social ao invés da exclusão.

No B rasil, o termo ES tem uma denotação mais radicalizada, pois é entendido como uma forma de apartação social não formalizada juridicamente.

Contudo, é importante elucidar como se desenvolvem, no meio acadêmico brasileiro, as discussões a esse respeito.

Nos anos 60 e 70 , foram comuns, no B rasil, estudos sobre a marginal idade e a desigual dade social; na década de 1980 esses termos foram substituídos pelo da pobreza e, na passagem da década de 1980 para a de 1990, a mesma questão social passa a ser denominada de exclusão social.

$\mathrm{N}$ esse sentido, $\mathrm{N}$ ascimento defende a idéia de que

[...] o país deixou para trás as discussões em torno das desigualdades regionais ou sociais, e mesmo 0 interesse pelo estudo dos pobres e seu modo de vida, para se concentrar no entendimento de um fenômeno que parecia novo: 0 da exclusão social. (N ascimento, 2000, p. 76)

Os primeiros teóricos a discutirem essa questão no Brasil foram Hélio J aguaribe e Cristóvam Buarque. Para o primeiro, a ES é fruto da crise econômica que teve início nos anos 80. Segundo esse autor:

a exclusão social seria, assim, o resultado do esgotamento do processo de integração social que estava inscrito no modelo econômico anteriormente vigente e cujo desenvolvimento comprometeria o nosso ideário de modernidade em ascender ao Primeiro M undo. (apud Nascimento, 1994)

Contrapondo-se a essa idéia, Cristóvam $B$ uarque defende que o fracasso do modelo econômico desvendou a ES que era preexistente à crise econômica dos anos 80. Contudo, afirma que a referida crise acelerou o processo de ES e o revestiu da forma de "apartação: criação de compartimentos diversos entre incluídos e excluídos" (apud idem, ibidem).

Partindo das afirmações desses dois estudiosos, podemos dizer que, na visão deles, a explicação para a ES encontra-se fundamentada na questão econômica, enquanto, para Telles (1992), o problema é também de cunho político. Sendo assim, ele sugere que a ES no Brasil ocorre devido à inexistência de um espaço público de igual dade que seja capaz de promover a integração social.

No desenvolvimento desse debate, cabe ressaltar as considerações de José de Souza $M$ artins a respeito do tema. Em consonância com Telles, M artins (1997) parte do princípio de que 0 aspecto econômico não é responsável pela ES. Em sua concepção, não existe exclusão e sim vítimas de processos sociais, políticos e econômicos excludentes. $M$ artins sustenta a idéia de que os excluídos fazem parte do sistema, ainda que seja negando-o, e são vítimas de problemas que foram criados no interior da sociedade. Por ser assim, não podem ser considerados como excluídos.

Já N ascimento defende a existência dessa categoria social e a conceitua da seguinte maneira: "O excluído não é apenas aquele que se encontra em situação de carência material, mas aquele que não é reconhecido como sujeito, que é estigmatizado, considerado nefasto ou perigoso à sociedade" (N ascimento, 1994, p. 61).

Nascimento discute as causas da exclusão social e afirma que esta possui fatores multidimensionais, de ordem econômica e 
política, que a impulsionam. Sendo assim, no aspecto econômico, 0 autor aponta como causas da ES os seguintes fatores: as metamorfoses no mundo do trabal ho; os impactos recentes das inovações tecnológicas; a desterritorialização provocada pelo movimento de internacionalização da economia, e o surgimento do desemprego estrutural e de longa duração. No aspecto político, o autor observa que a ausência de direitos coloca os indivíduos em situação de precariedade: sem ter direito a ter direito, o que é, segundo ele, uma forma suprema de exclusão.

Outro estudioso brasileiro que tem discutido amplamente essa questão é Pedro Demo. Em sua concepção, a exclusão social é um problema estrutural, pois é ocasionada pela própria lógica do sistema capitalista que promove a desigualdade social. A s causas desse problema, segundo ele, não são de ordem puramente econômica e, sim, sobretudo, política. Em sua visão, é impraticável falar de exclusão sem a conotação política que a envolve intrinsecamente (D emo, 1998, p. 33).

\section{As causas dos estudos de exclusão social}

Segundo M erton (1970), "a relação entre conhecimento e sociedade pressupõe uma teoria de método sociológico e de causação social". A inda nesse sentido, M erton afirma que as teorias na Sociologia do Conhecimento podem ser de ordem causal ou funcional e simbólica organicista ou de significado.

Tendo isso como base de análise, defendemos a idéia de que, nos estudos desenvolvidos por Elimar N ascimento e Pedro Demo a respeito da ES, as explicações dadas por eles para essa problemática social são de ordem causal. N esse sentido, é importante ressaltar e apresentar o desenvolvimento das idéias desses teóricos acerca das causas da exclusão social.

Elimar Nascimento - teórico brasileiro de Recife, doutor em Sociologia pela U niversidade René D escartes, Paris (1982), e pós-doutorado pela École des Hautes Études en Sciences Sociales (1992), onde estudou com A lain Touraine, pensador que também discute a exclusão social - atuou em diversas áreas do serviço público no Brasil e no exterior, principalmente docência, tendo sido professor nas U niversidades Federais da Paraíba e de Pernambuco ena U niversidade de B rasília, onde leciona atual mente.

$\mathrm{Na}$ análise de suas obras, percebe-se que o interesse desse teórico pela questão da exclusão social é mais significativo após o seu doutoramento na França, onde este tema ocupava grande espaço no meio acadêmico, pois é nesse período que surgem as suas primeiras publicações sobre 0 assunto. A ssim, com base em sua quatro obras aqui analisadas - "A exclusão social no B rasil: al gumas hipóteses de trabalho e quatro sugestões práticas" (1994), "A exclusão social na França e no B rasil: situações (aparentemente) invertidas, resultados (quase) similares?" (1994), "Globalização e exclusão social: fenômenos de urna nova crise da modernidade?" (1998) e "Dos excluídos necessários aos excluídos desnecessários" (2000) - , pode-se perceber como foi se ampliando, nesse autor, a visão sobre as causas e as possíveis soluções para o problema em questão.

Em seu texto " $A$ exclusão social no B rasil: algumas hipóteses de trabalho e quatro sugestões práticas" (1994), que é uma versão modificada do artigo "O fenômeno da exclusão social no B rasil", apresentado em um seminário em 1993, ele afirma que "o problema da exclusão social não se trata de um problema puramente econômico, mas de múltiplas dimensões" (Nascimento, 1994, p. 61).

No entanto, o autor, nesse artigo, se restringe a apresentar a dimensão histórica do problema no país, defendendo a hipótese de que "no caso do Brasil o fenômeno da exclusão social encontra-se encravado na sua própria história" (idem, ibidem) e que a sua persistência se dá em razão da "inexistência de um espaço público de iguais, inviabilizado por relações sociais excludentes, que impedem a montagem de um modelo econômico distributivista, base para a predominância de uma lógica social de integração" (idem, ibidem). Na conclusão desse texto, 0 autor propõe quatro sugestões para amenizar o problema da exclusão social: a) distribuição de al imentos, luta política em favor dos direitos humanos, criação de microempresas, controle da inflação e retomada dos investimentos econômicos; b) articulação dos órgãos estatais com associações societais (ONGs); c) 
desenvolvimento de políticas públicas voltadas para as iniciativas locais; d) apresentação de políticas públicas permanentes e territoriais. No conjunto, podemos afirmar que, nesse escrito, el e está apenas esboçando, de maneira simplificada, o que viria a ser seus trabal hos posteriores.

Já em seu segundo texto, aqui analisado, "A exclusão social na França e no Brasil: situações (aparentemente) invertidas, resul tados (quase) similares?" (1994), o autor apresenta o histórico do desenvolvimento do debate acerca do conceito de exclusão social na França e no B rasil e conclui 0 artigo fazendo uma comparação entre a representação da idéia de ES nesses dois países. Nessa análise comparativa, afirma que na $F$ rança a $E S$ é apresentada como resultado do fracasso da sociedade moderna, como expressão de seu esgotamento, eno B rasil o mesmo problema é entendido como resultado da inexistência da modernidade. Segundo ele, "é como se na situação brasil eira houvesse fal ta de modernidade, enquanto na francesa haveria 'excesso'" (N ascimento, 1994, p. 302).

Contudo, ele afirma que os dois países têm em comum o fato de terem falido na construção de uma sociedade de iguais.

No terceiro texto analisado, "G lobalização e exclusão social: fenômenos de uma nova crise da modernidade?" (1998), o autor discute, primeiramente, os conceitos de modernidade e pós-modernidade, fundamentando-se, sobretudo, em autores franceses. Depois aborda a questão da globalização e apenas no final passa a discutir a ES.

Todas as discussões feitas nesse texto sobre modernidade, pós-modernidade, globalização e exclusão social estão voltadas para a fundamentação da sua hipótese de que "a exclusão é incompatível com a modernidade" (N ascimento, 1998, p. 90).

No texto "Dos excluídos necessários aos excluídos desnecessários" (2000), Elimar amplia a sua análise sobre as múltiplas dimensões da exclusão social. A lém dos fatores histórico e político, o autor aponta os aspectos geográfico, e social e desenvolve, ainda mais, 0 aspecto econômico.

A ssim, na dimensão geográfica, el e observa que há lugares estigmatizados em que se nasce e cresce excluído; na dimensão social, ele entende que existem indivíduos que perderam todo e qualquer vínculo social e, na dimensão econômica, ele percebe a impossibilidade de algumas pessoas terem acesso aos bens materiais e simbólicos da sociedade e de encontrarem um lugar no mundo do trabalho.

Toda essa explanação a respeito das múltiplas dimensões da exclusão social tem como objetivo expor a transição, do excluído, do caráter de necessário ao sistema econômico para 0 de desnecessário. Desse modo, 0 autor afirma que, historicamente no $B$ rasil, os índios, os negros e os trabalhadores rurais foram excluídos, mas que, no entanto, estes eram excluídos necessários ao desenvolvimento do país. Contudo, nas últimas décadas, pelo fato de o crescimento industrial não ter gerado mais emprego como nas décadas anteriores e de 0 setor secundário ter diminuído o seu contingente de empregados, o excluído tornou-se economicamente desnecessário, politicamente incômodo e social mente ameaçador, podendo, portanto, ser eliminado fisicamente.

Diante desse quadro, 0 autor aponta como solução para o problema não mais saídas que apenas 0 amenizem, mas sim a ruptura com 0 modelo econômico predominante, o que deve ocorrer por meio do conflito social. Caso isso não ocorra, o autor faz a sombria previsão de que poderá ocorrer no Brasil a forma extrema de exclusão social: a apartação social.

0 outro sociólogo que discute a problemática da exclusão social, e que teve algumas de suas obras analisadas neste trabalho, é Pedro Demo, também doutor em Sociologia, mas com formação e atuação diversa da de Elimar N ascimento. Graduado e doutorado em Sociologia pela Universidade de Saarbuecken, na A lemanha, atuou em universidades públicas e privadas no $B$ rasil e, atual mente, é professor da UnB no Departamento de Serviço Social. A utor de vários livros, sobretudo na área de $M$ etodologia e Educação, Pedro Demo foi técnico do Instituto de Pesquisa Econômica A plicada (Ipea) de 1975 a 1994 e tem se dedicado a escrever sobre a exclusão social, em razão do vasto conhecimento adquirido acerca da política social brasileira nesse instituto.

Hodiernamente, Pedro Demo tornou-se um crítico do I pea e, principalmente, do ex- 
presidente do B rasil Fernando H enrique Cardoso, por entender que este fez uso tendencioso dos dados estatísticos apresentados pelo órgão, dados estes que procuram mostrar a redução da pobreza absoluta, mas, contudo, acobertam o aumento da pobreza relativa no B rasil.

As obras de Pedro Demo anal isadas neste trabalho - O Charme da exclusão social (1998), Combate à pobreza: desenvolvimento como oportunidade (1996) e o seu recente artigo "Globalização da exclusão social" (2002) - procuram explicar a exclusão social com fundamento nas teorias de causalidade ou funcional, pois partem do princípio de que o modo como o capitalismo está estruturado gera a exclusão social, pois, segundo ele, esse sistema é incompatível com a justiça social.

Em Charme da exclusão social, Pedro Demo discute o conceito de exclusão, fundamentando-se em vários teóricos, sobretudo de origem francesa e inglesa, e estende essa discussão ao Brasil, afirmando que tradicionalmente, no país, o problema da exclusão social tem sido tratado de maneira assistencialista, por meio de medidas paliativas, e que os teóricos brasileiros sobressal tam os fatores econômicos como sendo os responsáveis pela exclusão. Demo critica esses teóricos e observa que esse problema é causado muito mais por fatores de ordem política do que econômica.

A ssim sendo, Demo (1998) aponta que a carência material é a casca externa da desigualdade social, cujo cerne está na pobreza política. Para combater a pobreza política, será necessário reinventar a cidadania do excluído, pois esta é mais comprometedora que a pobreza material.

A outra obra do autor analisada, Combate à pobreza: desenvolvimento como oportunidade, trata-se de uma análise/resposta ao texto oficial do I pea/PNDU (1996) sobre as condições do desenvolvimento humano, mostrando que 0 B rasil jamais conseguiu atingir a dinâmica da redução da pobreza relativa.

A s críticas ao relatório sobre o desenvolvimento humano no Brasil - 1996 referem-se principal mente ao fato de este reduzir a pobreza à insuficiência de renda, não vislumbrando assim a trama política do fenômeno da pobreza, fator decisivo, segundo Pedro Demo, para o crescimento dela: “É nossa hipótese de trabal ho que o centro da pobreza não é a insuficiência de renda, mas a exclusão política, ou seja, o problema da desigualdade" (Demo, 1998, p. 94).

$\mathrm{N}$ a concepção desse autor, a condição mais intensa de pobreza é a exclusão social de caráter político, a qual é historicamente produzida, mantida e cultivada. Para reverter essa situação, 0 autor indica como fator essencial a educação de qualidade, tendo em vista que ela pode colaborar na construção da competência humana histórica, voltada a fazer a oportunidade de desenvolvimento.

Pedro Demo volta a discutir a questão da exclusão social em um recente artigo intitulado "Global ização da exclusão social". N esse texto, o autor faz críticas ao relatório do Banco Interamericano do Desenvolvimento (BID), sobre a desigualdade na A mérica Latina. Ele afirma que a globalização, que acenava para um horizonte de aproximação dos povos e de permuta de vantagens comparativas, ao contrário disso, tem ocasionado um aprofundamento, sem precedentes, da crise econômica e social, avançando, inclusive, sobre as regiões antes marcadas pelo Estado do Bem-Estar Social.

As críticas do autor ao relatório recaem sobre o fato de ele reduzir a pobreza à carência material, ignorando a sua face política, sempre mais drástica. Considerando tal situação, 0 autor propõe como solução para o problema a construção da cidadania por meio da educação, pois, segundo ele, "é mister afirmar que a desconcentração da renda é, sobretudo, um fenômeno político de conquista histórica. A cidadania ainda é a cláusula central da eqüidade" (idem, 2002, p. 17).

\section{Considerações finais}

Considerando o que foi discorrido até 0 momento, percebe-se que esses teóricos, apesar de trabalharem em uma mesma instituição de educação e se fundamentarem, praticamente, nos mesmos pensadores de origem francesa que discutem a exclusão social, têm concepções e propostas de solução diferente acerca do tema em questão.

Nos textos de Nascimento, é clara a preocupação do autor em apresentar e discutir 
os diversos conceitos de exclusão social. Já Pedro Demo não demonstra essa preocupação, pois, segundo ele, "mudam conceitos e teorias, mas a pobreza é, mais ou menos, a mesma" (Demo, 1998, p. 99).

Outra observação que pode ser feita é quanto ao aprofundamento da discussão referente ao tema da exclusão social nos dois teóricos. Enquanto $\mathrm{N}$ ascimento, em cada um de seus textos analisados, procura desenvolver mais a discussão do tema, ampliando o seu conceito de exclusão social e apresentando novas dimensões do problema, Demo se restringe a repetir a idéia de que a exclusão social é um problema muito mais de ordem política do que econômica, usando argumentos repetitivos e redundantes.

Q uanto aos fatores geradores da exclusão social, ambos defendem que este é um problema estrutural ocasionado pelo próprio sistema capitalista. No entanto, divergem quanto às soluções propostas - enquanto $\mathrm{N}$ ascimento sugere a ruptura com o sistema econômico vigente, por meio do conflito social, Demo propõe como solução o desenvolvimento da educação, por entender que ela será capaz de formar cidadãos capazes de lutar por justiça social, combatendo, assim, a exclusão social.

Isto posto, convém lembrar que o debate sobre a exclusão social no $B$ rasil não se resume a esses teóricos eque, para melhor compreensão e discussão do tema, torna-se necessária a análise do pensamento de outros teóricos que discutem essa questão, trabalho que se pretende realizar futuramente de modo mais detido.

A bstract: The present work tries to disouss the social exclusion under the Sociology of the Knowledge' s prim. This way, basing on Merton, who af firms that this science takes interest in the relation between the knowledge and other existing factors of the society, the article shows a detailed report about the evolution of the theoretical debate about the theme, it disouss the question of social exclusion from two studious Brazilian men on: Elimar Pinheiro do Nascimento and Pedro Demo, and it correlates the existent basis of the production of these theoretical men with their respective intellective productions.

K ey-words: social exclusion; sociologycal theory; gldoalization.

R eferências

DEM O, Pedro. 0 charme da exclusão social. Campinas: A utores A ssociados, 1998.

. Combate à pobreza: desenvolvimento como oportunidade. Campinas: Autores Associados, 1996.

Globalização da exclusão social. Brasília, 2002. Disponível em http://redebonja.cbj.br/ielusc/ necom/textos/nec. H tml. A cesso em 12 fev. 2002.

M A RTINS, José de Souza. Exclusão social e a nova desigualdade. São Paulo: Paulus, 1997. [Coleção Temas de A tualidade]

MERTON, RobertK. Sociologia: teoria e estrutura. São Paulo: M estre J ou, s.d.

NA SCIMENTO, Elimar Pinheiro. G lobalização e exclusão social: fenômenos de uma nova crise da modernidade? In: DOWBOR, Ladislau \& outros. Desafios da gl obalização. Petrópolis: Vozes, 1998.

. A exclusão social no Brasil: algumas hipóteses de trabal ho e quatro sugestões práticas. In: Cadernos do CEAS, n. 152, Centro de Estudos e A ção Social, Salvador, 1994.

A exclusão social na França e no Brasil: situações (aparentemente) invertidas, resultados (quase) similares? In: DINIZ, Eli \& outros. O Brasil no rastro da crise. São Paulo: A npocs/ I pea/ Hucitec, 1994.

Dos excluídos necessários aos excluídos desnecessários. In: BU RSZTY N, M arcel (Org.). No meio da rua. Nômades, excluídos e viradores. Rio deJ aneiro: Garamond, 2000.

ReCEBIDO EM NOVEMBRO DE 2004 A PROVADO EM MARÇO DE 2004 